University of Nebraska - Lincoln

DigitalCommons@University of Nebraska - Lincoln

Faculty Publications: Department of

Entomology

Entomology, Department of

1998

Comparison of Esterases Between Life Stages and Sexes of

Resistant and Susceptible Strains of German Cockroach

(Dictyoptera: Blattellidae)

No-Joong Park

University of Nebraska-Lincoln

Shripat T. Kamble

Universitiy of Nebraska--Lincoln, skamble1@unl.edu

Follow this and additional works at: https://digitalcommons.unl.edu/entomologyfacpub

Part of the Entomology Commons

Park, No-Joong and Kamble, Shripat T., "Comparison of Esterases Between Life Stages and Sexes of Resistant and Susceptible Strains of German Cockroach (Dictyoptera: Blattellidae)" (1998). Faculty Publications: Department of Entomology. 310.

https://digitalcommons.unl.edu/entomologyfacpub/310

This Article is brought to you for free and open access by the Entomology, Department of at DigitalCommons@University of Nebraska - Lincoln. It has been accepted for inclusion in Faculty Publications: Department of Entomology by an authorized administrator of DigitalCommons@University of Nebraska - Lincoln. 


\title{
Comparison of Esterases Between Life Stages and Sexes of Resistant and Susceptible Strains of German Cockroach (Dictyoptera: Blattellidae)
}

\author{
NO-JOONG PARK AND SHRIPAT T. KAMBLE \\ Department of Entomology, University of Nebraska-Lincoln, Lincoln, NE 68583-0816
}

\begin{abstract}
J. Econ. Entomol, 91 (5): 1051-1057 (1998)
ABSTRACT Esterase activity between the resistant Crawford and susceptible CSMA strains of German cockroach, Blattella gemmanica (L.), was compared with the substrates $\alpha$-and $\beta$-naphthyl acetate across sex and nymphal age classes. Esterase isozyme analysis with native polyacrylamide gel electrophoresis also was conducted to identify quantitative and qualitative differences between strains, sexes, and age classes. The Crawford strain was highly resistant to cypermethrin, propoxur, and permethrin with a resistant ratio (RR) of $17.26,15.75$, and 13.53, respectively, and mildly resistant to chlorpyrifos (RR 5.62). The $\alpha$-NA and $\beta$-NA esterase activities in the Crawford strain were significantly higher than those activities in the CSMA strain in both nymphal and adult stages. In the Crawford strain, the enzyme activity in nymphs was significantly higher than that in adults, but such differences were not observed in the CSMA strain. The mobile isozymes $a$ and $c$ stained more intensely than others in every developmental stage and sex of both strains but showed greater intensity in the Crawford strain. Another intensely stained isozyme $b$ was observed only in the homogenates from the Crawford strain. The combination of isozyme $b$ and the overproduced isozyme $a$ and $c$ in the Crawford strain seems to be responsible for the difference in total esterase activity between the CSMA and Crawford strains.
\end{abstract}

KEY WORDS Blattella germanica, insecticide resistance, esterase, isozymes

The Griman COCKRoACH, Blattella germanica (L.), is a major pest in households, hospitals, and common food-processing establishments (Cochran et al. 1972). It is also medically important because of its ability to transmit organisms that cause human diseases (Frishman and Alcamo 1977).

Insecticides are commonly applied to control German cockroach. Continuous use of insecticides has led to the development of resistance in German cockroaches to chlorinated hydrocarbons (Grayson 1963), organophosphates (Rust and Reierson 1991), carbamates (Schal 1988), and pyrethroids (Cochran 1989, Zhai and Robinson 1992).

Several researchers have reported that the combined effects of enhanced oxidative and hydrolytic metabolic enzyme activity are associated with organophosphate- and carbamate-resistant German cockroaches (Siegfried and Scott 1992, Valles et al. 1994, Prabhakaran and Kamble 1995). Esterases are classified as hydrolases, a large and diverse group of enzymes that catalyze the hydrolysis of a wide range of aliphatic and aromatic esters, choline esters, and organophorous compounds (Dauterman 1985). Insect hydrolases exist in multiple forms that can be resolved by electrophoresis and detected using simple spectrophotometric assays with substrates such as the acetate and butyrate esters of $p$-nitrophenol and acetate

\footnotetext{
${ }^{1}$ To whom reprint requests should be addressed.
}

esters of $\alpha$ - and $\beta$-naphthol (Soderlund and Bloomquist 1990). The role of esterases in insecticide resistance by the German cockroach has not been clearly determined because of their multiple forms and nonspecific substrate affinity (Maa and Terriere 1983). It has been suggested that the overproduction of the esterase isozyme $\mathrm{E} 6 \mathrm{might}$ be responsible for the sequestration of insecticidal compounds rather than hydrolysis in resistant German cockroaches (Prabhakaran and Kamble 1995). However, an important aspect that remains unexamined is that different isozymes may be overexpressed in different resistant strains. Insecticide resistance by sequestration also was reported in German cockroaches (Prabhakaran and Kamble 1995, Scharf et al. 1997), peach-potato aphids (Devonshire and Moores 1982), mosquitoes (Cuany et al. 1993), and rice brown planthoppers (Chen and Sun 1994). After confirmation of their interaction with insecticides, these enzymes can be routinely used as reliable biochemical markers for resistance monitoring with a suitable detection method depending on insect species (Pasteur and Georghiou 1989, Byrne and Devonshire 1991, AbdelAal et al. 1992).

The objective of this research was to determine and compare esterase activity between the CSMA susceptible and Crawford resistant strains of German cockroach. In addition, we report the isozyme patterns of esterase as a result of age, developmental stage, and 
sex, as separated by native polyacrylamide gel electrophoresis.

\section{Materials and Methods}

Chemicals. Analytical standard grade insecticides were dissolved and diluted in reagent grade acetone for use in topical bioassays. Insecticides used included chlorpyrifos (>99\% [AI]), propoxur (>99\% [AI]), permethrin (74\% cis: $25 \%$ trans [AI]), and cypermethrin (40\% cis: $58 \%$ trans [AI]). All insecticides were obtained from ChemService (West Chester, PA). All biochenical and electrophoresis reagents were obtained from Sigma (St. Louis, MO) and BioRad (Hercules, CA).

Insects. Insecticide-susceptible (CSMA) and resistant (Crawford) German cockroaches were used in all tests. The CSMA strain was obtained from Cornell University, Ithaca, NY, through B. Siegfried, University of Nebraska, Lincoln, NE, in 1991, and has been reared continuously without selection pressure. The Crawford strain is a supposed multiresistant strain obtained from M. Ross, Virginia Polytechnic Institute and State University, Blacksburg, VA, in 1996. Both strains of German cockroach were reared on Purina dog chow (Ralston Purina, St. Louis, MO) and water, and maintained in Plexiglas containers $(30.3 \mathrm{~cm}$ wide by $30.3 \mathrm{~cm}$ high by $30.3 \mathrm{~cm}$ deep). Cockroach colonies were maintained at $25 \pm 2{ }^{\circ} \mathrm{C}, 60 \pm 10 \% \mathrm{RH}$, and a photoperiod of 12:12 (L:D) h. For life stage analyses, newly hatched nymphs from both strains were collected from gravid female rearing containers at 2- to 3-d intervals, and maintained in separate containers.

Topical Assays. Groups of 10 adult cockroach males were anesthetized with carbon dioxide and topically treated with $0.5 \mu \mathrm{l}$ of insecticide solution on the 1st abdominal sternite. Five to 6 concentrations of each insecticide were tested per strain with 3 replications. Cockroaches were confined in petri dishes and held at $25 \pm 2^{\circ} \mathrm{C}, 60 \pm 10 \% \mathrm{RH}$, and a photoperiod of $12: 12$ (L:D) h. Mortality (no response to probing) was recorded $24 \mathrm{~h}$ after treatment, and analyzed by probit analysis (Raymond 1985) after correction by Abbott's formula (Abbott 1925).

Preparation of Enzyme. For electrophoresis and enzyme assays, 10-50 nymphal or 10 adult cockroaches according to the developmental stages were homogenized in a motor-driven glass homogenizer
(Duall Tissue Grinder $3 \mathrm{ml}$, Fisher, Pittsburgh, PA) with 1.5-4.5 $\mathrm{ml}$ of $0.01 \mathrm{M}$ Tris buffer $(\mathrm{pH} 7.8)$ in an ice bath. The homogenate was centrifuged for $20 \mathrm{~min}$ at $4^{\circ} \mathrm{C}$ at $10,000 \times g$ and the supernatant was filtered through a $1-\mu \mathrm{m}$ glass wool membrane syringe prefilter (Fisher) and was used as the enzyme source for esterase activity assays and native polyacrylamide gel electrophoresis.

Protein and Esterase Assay. The protein concentration was determined by the method of Bradford (1976). Bovine serum albumin was used to obtain the standard curve. Total nonspecific esterase activity was measured according to the technique of Van Asperen (1962), with some modifications. The enzyme assay was conducted by measuring the production of $\alpha$ - and $\beta$-naphthol from the substrates of $\alpha$ - and $\beta$-naphthyl acetate, respectively. Each sample was added to make a final volume of $1 \mathrm{ml}$ of reaction mixture, containing $6.25 \mathrm{mM}$ substrate in $0.01 \mathrm{M}$ Tris buffer ( $\mathrm{pH} 7.8$ ). The reaction was initiated by addition of $20 \mu$ l of enzyme solution containing $2.5 \mu \mathrm{g}$ of protein and incubated at $38^{\circ} \mathrm{C}$. The reaction was stopped after $10 \mathrm{~min}$ and color was developed by addition of $166 \mu \mathrm{l}$ of stop solution $(0.3 \%$ diazo blue B in $3.5 \%$ sodium lauryl sulfate). The absorbance at $600 \mathrm{~nm}$ for $\alpha$-naphthol or $555 \mathrm{~nm}$ for $\beta$-naphthol was read $10 \mathrm{~min}$ later against an enzyme blank, and the concentration of hydrolyzed substrate was determined from the standard curves of $\alpha$-naphthol and $\beta$-naphthol, respectively.

Gel Electrophoresis. Native polyacrylamide gel electrophoresis (native PAGE) was performed in a vertical electrophoresis unit (Protean II mini electrophoresis cell, Bio-Rad) by using a 7.5\% separating gel and $2.5 \%$ stacking gel, with a discontinuous tris-glycine buffer system. Samples of prepared enzyme were diluted 1.5-fold with stacking gel buffer so that they contained $10 \%$ glycerol and $0.002 \%$ bromophenol blue as tracking dye, and $20 \mu \mathrm{g}$ of protein for each sample was loaded onto the gel. Electrophoresis was conducted at a constant $100 \mathrm{~V}$ for $1.5 \mathrm{~h}$ in a $4^{\circ} \mathrm{C}$ cold chamber. After running, the gels were placed in cold $0.5 \mathrm{M}$ boric acid solution for $10 \mathrm{~min}$. Gels were stained for esterase activity in $100 \mathrm{ml}$ of $0.05 \mathrm{M}$ sodium phosphate buffer ( $\mathrm{pH} 7.0), 0.5 \%$ (by volume) $50 \mathrm{mM}$ $\alpha$-naphthyl acetate only or with $\alpha$-naphthyl propionate and $\alpha$-naphthyl butyrate dissolved in acetone, and $0.04 \mathrm{~g}$ of fast blue RR salt to visualize naphthol. The incubation continued at room temperature for 30

Table 1. Toxicities of insecticides to male adults of CSMA (susceptible) and Crawford (resistant) German cockroaches

\begin{tabular}{|c|c|c|c|c|c|c|}
\hline Insecticide & Strain & $n$ & Slope (SE) & $\begin{array}{c}\mathrm{LD}_{50}(\mu \mathrm{g} / \mathrm{insect} \\
95 \% \mathrm{CI})\end{array}$ & $x^{2}$ & $\mathrm{RR}^{\prime \prime}$ \\
\hline \multirow[t]{2}{*}{ Chlorpyrifos } & CSMA & 180 & $5.89(0.986)$ & $0.358(0.308-0.415)$ & 0.831 & 1.00 \\
\hline & Crawford & 180 & $3.33(0.564)$ & $2.012(1.572-2.455)$ & 1.115 & 5.62 \\
\hline \multirow[t]{2}{*}{ Propoxur } & CSMA & 180 & $3.06(0.401)$ & $0.295(0.241-0.361)$ & 2.804 & 1.00 \\
\hline & Crawford & 180 & $1.30(0.264)$ & $4.645(3.041-6.938)$ & 2.461 & 15.75 \\
\hline \multirow[t]{2}{*}{ Permethrin } & CSMA & 210 & $2.87(0.424)$ & $0.074\{0.060-0.094\}$ & 6.363 & 1.00 \\
\hline & Crawford & 210 & $1.72(0.330)$ & $1.001(0.698-1.850\rangle$ & 7.123 & 13.53 \\
\hline \multirow[t]{2}{*}{ Cypermethrin } & CSMA & 210 & $4.03(0.566)$ & $0.027\langle 0.023-0.033\rangle$ & 1.889 & 1.00 \\
\hline & Crawford & 210 & $2.84(0.311)$ & $0.466\langle 0.360-0.630\}$ & 3.939 & 17.26 \\
\hline
\end{tabular}

${ }^{a} \mathrm{RR}$; resistance ratio, $\mathrm{LD}_{50}$ from Crawford strain/LD $\mathrm{L}_{50}$ from CSMA strain. 
Table 2. Artivity of nonspecific esterase from CSMA (susceptible) and Crawford (resistant) strains of German cockroaches toward a-naphthyl acetate according to the developmental stages

\begin{tabular}{|c|c|c|c|c|}
\hline & \multirow{2}{*}{ Sex or agge } & \multicolumn{2}{|c|}{$\alpha$-NA esterase activity ( $\mathrm{nmole} / \mathrm{min} / \mathrm{mg}$ protein) } & \multirow{2}{*}{$\mathrm{R} / \mathrm{S}^{n}$} \\
\hline & & Crawford & CSMA & \\
\hline \multirow[t]{8}{*}{ Nymph } & newly hatched & $2,266.04 \pm 108.046$ & $744.13 \pm 62.860$ & 3.05 \\
\hline & 1 wk old & $1,988.90 \pm 227.856$ & $1040.13 \pm 80.818$ & 1.91 \\
\hline & 2 wh old & $2,025.47 \pm 144.507$ & $888.32 \pm 33.355$ & 2.28 \\
\hline & 3 wk old & $1,728.74 \pm 108.138$ & $949.69 \pm 109.035$ & 1.82 \\
\hline & 4 wh old & $1,745.17 \pm 107.083$ & $917.79 \pm 100.106$ & 1.90 \\
\hline & 5 wk old & $2,295.37 \pm 120.537$ & $1020.13 \pm 127.308$ & 2.25 \\
\hline & 6 wk old & $1,794.23 \pm 90.185$ & $1016.71 \pm 60.901$ & 1.76 \\
\hline & 7 wk old & $1,404.71 \pm 129.658$ & $916.67 \pm 115.439$ & 2.45 \\
\hline \multirow[t]{4}{*}{ Adult } & newly emerged $\delta$ & $1,500.51 \pm 164.945$ & $857.47 \pm 60.128$ & 1.75 \\
\hline & newly emenged $q$ & $1,213.85 \pm 140.867$ & $803.75 \pm 53.813$ & 1.51 \\
\hline & 5 wk-old $\delta$ & $1,612.90 \pm 280.504$ & $949.47 \pm 107.920$ & 1.70 \\
\hline & 5 wk-old $?$ & $1,300.90 \pm 51.172$ & $851.75 \pm 103.694$ & 1.53 \\
\hline
\end{tabular}

Mein \pm SEM of 3 preparations with 3 determinations each $(n=9)$. All values of each stage or sex of Crawford strain are significantly larger thun those of the CSMA strain ( $P<0.01$, Student's $t$-test).

" $\mathrm{R} / \mathrm{S}$; esterase activity from Crawford/esterase activity from CSMA.

min unless otherwise noted. The substrate-dye solution containing the $3 \alpha$-naphthyl esters provided higher intensity and better resolution of esterase isozymes than the solution with other combinations or each of substrate alone. After staining, gels were transferred to a destaining chamber containing $5 \%$ acetic acid solution. Gels and cellophane membranes were placed in the drying solution containing $0.3 \%$ glycerol and 20\% methyl alcohol, and the fixed gels were dried between 2 sheets of filter paper in a gel dryer (model 583 Gel Dryer, Bio-Rad).

\section{Results}

The toxicities of 4 insecticides belonging to organophosphate, carbamate, and pyrethroid classes to Crawford (resistant) and CSMA (susceptible) strains of German cockroach are presented in Table 1. The $\mathrm{LD}_{50}$, values from the Crawford strain were higher than those from the CSMA strain for all of the 4 insecticides tested. The resistance ratio (RR) values derived from the formula $R R=L_{50}$ of Crawford strain $/ L_{1} D_{50}$ of CSMA strain also are presented in the same table. The resistant Crawford strain showed high levels of resistance to cypermethrin, propoxur, permethrin, and chlorpyrifos with resistance ratio of $17.26,15.75,13.53$, and 5.62 , respectively.

Table 2 shows the $\alpha$-naphthyl acetate ( $\alpha$-NA) esterase activity of the CSMA and Crawford strains, according to nymphal age classes. The R/S values calculated from the formula $\mathrm{R} / \mathrm{S}=$ esterase activity from Crawford strain/esterase activity from CSMA strain also are presented in the same table. Significant difference between CSMA and Crawford strains was observed at every stage. The $\alpha$-NA esterase activities in nymphal stages were much higher in the Crawford strain than those in CSMA with the range of $R / S$ value from 1.76- to 3.05-fold, which equates to 1.76- to 3.05fold higher enzyme activity over CSMA. In adults, the enzyme activity was higher in the Crawford strain than in CSMA strain regardless of sex or age with the range of $R / S$ value from 1.51 - to 1.75 -fold.

Table 3 shows the $\beta$-naphthyl acetate $(\beta$-NA) esterase activity from the CSMA and Crawford strains according to developmental stages and sex. The difference of $\beta$-NA esterase activities between the 2

Tnble 3. Activity of nouspecific esterase from CSMA (susceptible) and Crawford (resistant) strains of German cockrouches toward Bnmaphthyl acetate according to the developmental stages

\begin{tabular}{|c|c|c|c|c|}
\hline & \multirow{2}{*}{ Sex or age } & \multicolumn{2}{|c|}{$\beta$-NA esterase activity (nmole $/ \mathrm{min} / \mathrm{mg}$ protein) } & \multirow{2}{*}{$\mathrm{R} / \mathrm{S}^{\prime}$} \\
\hline & & Crawford & CSMA & \\
\hline \multirow[t]{8}{*}{ Nymplı } & newly hatched & $2,652.37 \pm 112.966$ & $863.31 \pm 96.811$ & 3.07 \\
\hline & 1 wk old & $2,154.42 \pm 160.641$ & $1,330.91 \pm 148.708$ & 1.62 \\
\hline & 2 wk old & $2,421.82 \pm 155.715$ & $628.82 \pm 69.750$ & 3.85 \\
\hline & 3 wk old & $1,874.65 \pm 81.584$ & $790.24 \pm 85.370$ & 2.37 \\
\hline & 4 wk old & $1,460.94 \pm 106.245$ & $956.13 \pm 119.932$ & 1.53 \\
\hline & 5 wk old & $2,388.52 \pm 31.998$ & $1,336.17 \pm 166.109$ & 1.79 \\
\hline & 6 wk old & $1,897.79 \pm 73.961$ & $1,161.95 \pm 30.622$ & 1.63 \\
\hline & 7 wk old & $1,708.26 \pm 120.572$ & $899.20 \pm 156.897$ & 1.90 \\
\hline \multirow[t]{4}{*}{ Adult } & newly emerged $\delta$ & $1,829.49 \pm 276.089$ & $1,138.44 \pm 167.984$ & 1.61 \\
\hline & newly emerged $q$ & $1,575.05 \pm 117.879$ & $1,092.28 \pm 63.438$ & 1.44 \\
\hline & 5 wk-old $\delta$ & $1,800.09 \pm 279.690$ & $925.40 \pm 184.015$ & 1.95 \\
\hline & 5 wh-old 9 & $1,621.82 \pm 70.070$ & $616.98 \pm 88.107$ & 2.63 \\
\hline
\end{tabular}

Mean \pm SEM of 3 preparations with 3 determinations each $(n=9)$. All values of each stage or sex of Crawford strain are significantly larger than those of the CSMA strain ( $P<0.01$, Student's $t$-test).

" R/S; esterase activity from Crawford/esterase activity from CSMA. 


\section{Crawford nymph}

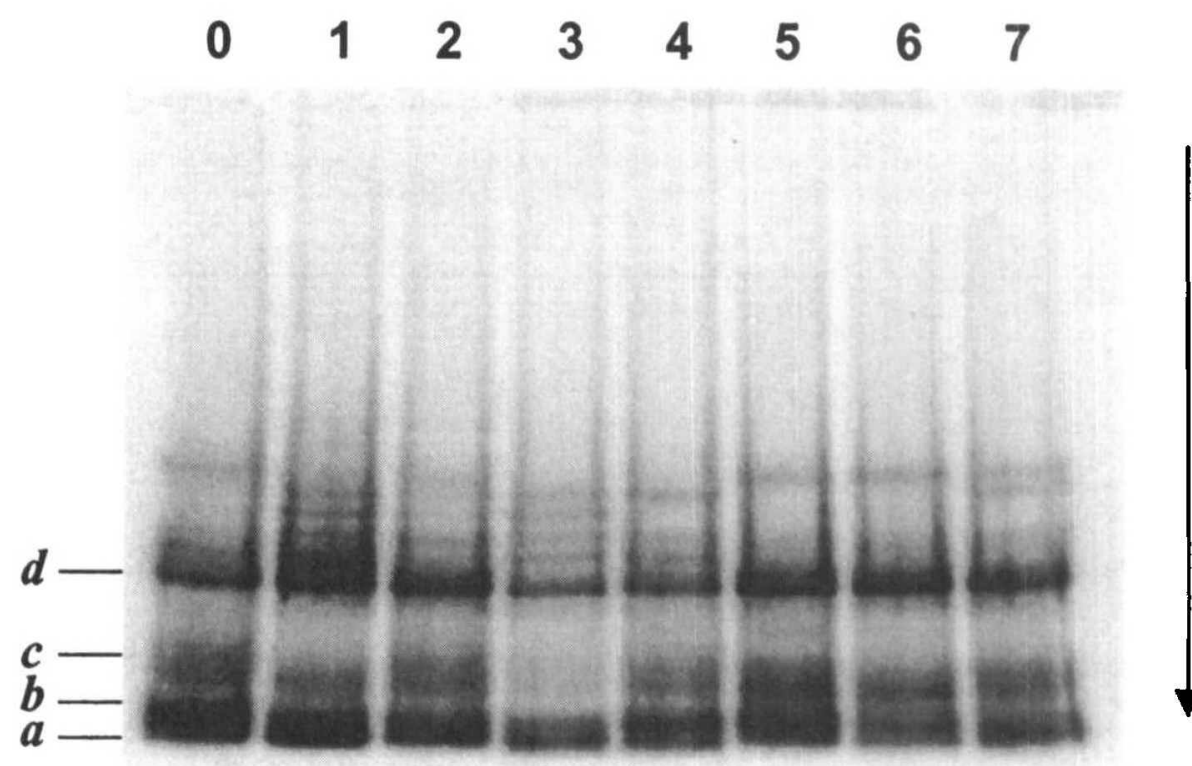

\section{CSMA nymph}

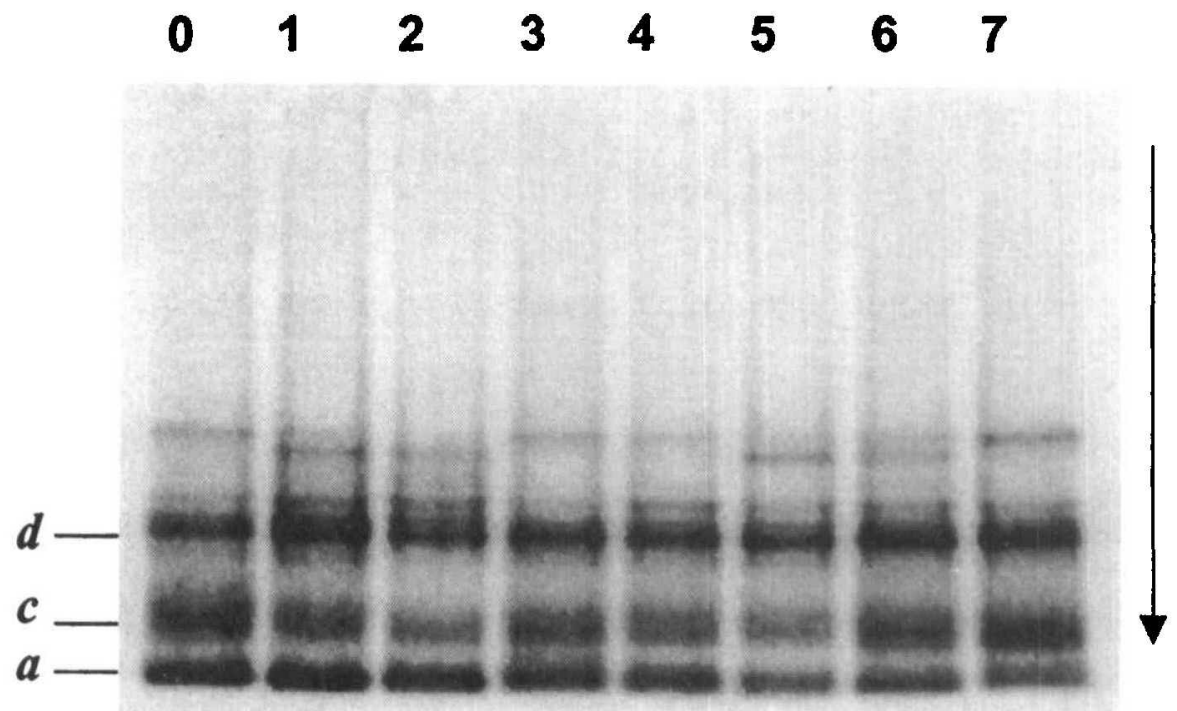

Fig. 1. Nonspecific esterase isozymes from nymphs of the Crawford and CSMA strains of German cockroach, separated by native polyacrylamide gel electrophoresis. Esterase isozymes were visualized with $\alpha$-naphthyl acetate, $\alpha$-niphthyl propionate, and $\alpha$-naphthyl butyrate as substrates. Letters $a-d$ indicate the 4 major isozyme bands of increasing mobility in the native gels. Numbers above each lane indicate nymphal age (week). See text for descriptions of sample preparation, gel running conditions, and staining techniques.

strains, and between nymphal and adult stages, was essentially identical to those for $\alpha$-NA esterase activities. The $\beta$-NA esterase activities in nymphs of Crawford strain are 1.56- to 4.26-fold higher than those of CSMA strain.
Native PAGE revealed that homogenate samples from both nymphs and adults of the Crawford and CSMA strains, as stained by $3 \alpha$-naphtholic esters, contain $\approx 10$ esterase isozymes. Five major bands with a high capability of hydrolyzing $\alpha$-naphtholic esters 


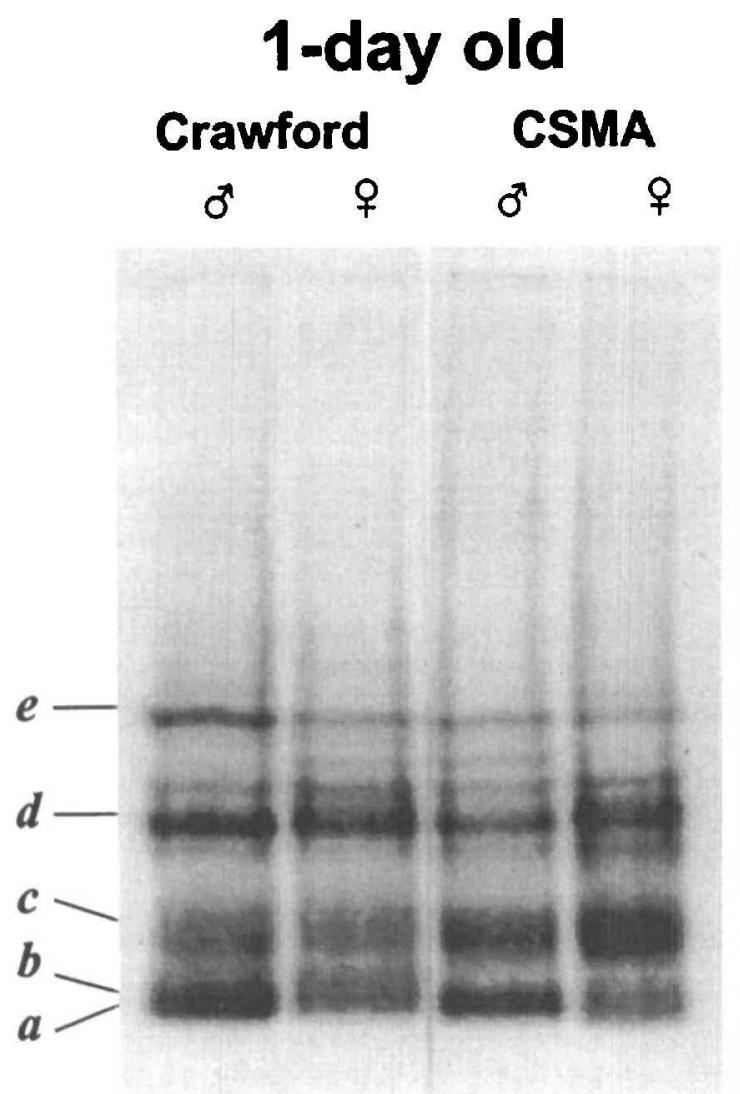

\section{5-week}

\section{Crawford CSMA}

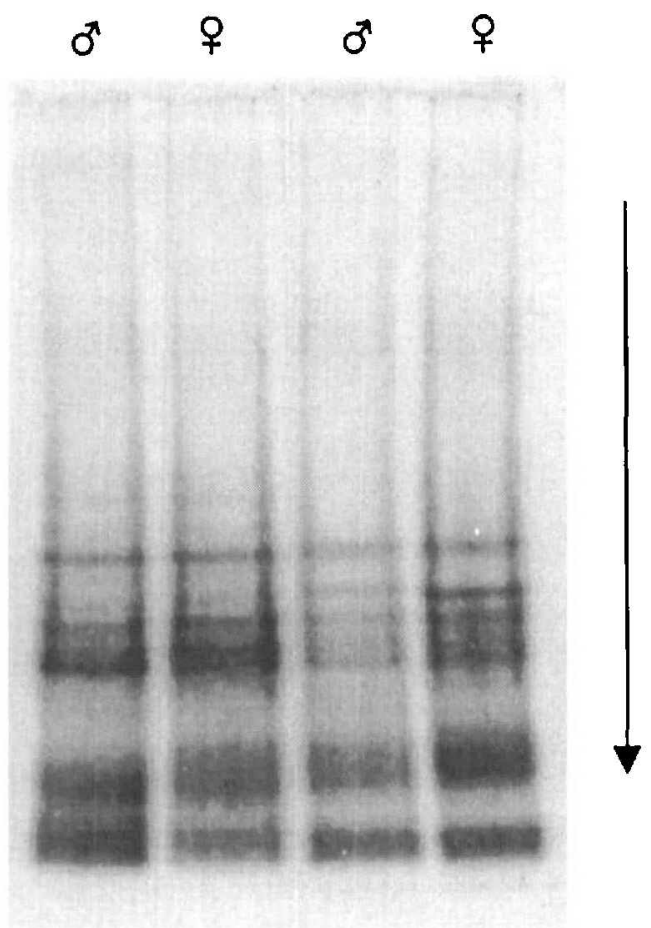

Fig. 2. Nonspecific esterase isozymes from adults of the Crawford and CSMA strains of German cockroach, separated by native polyacrylamide gel electrophoresis; new: newly emerged adults, old: 5 -wk-old adults. Letters $a-e$ indicate the 5 major isoz'me bands of increasing mobility in the native gels. See the text for details.

were designated as $a, b, c, d$, and $e$ according to their native PAGF mobility (Figs. 1-3). The most intensely staining bands from both nymphs and adults of the Crawford and CSMA strains were the esterase $a$ and $c$ (Figs. 1 and 2). Esterase $b$, the 2 nd band from the bottom of the gel, was visible only in Crawford strain (Figs. 1-3). Esterase $e$ appeared at a same migration rate only in adults (Figs. 2 and 3); thus, this esterase seems to be continuously existing as a constant moIecular form in adults. The qualitative differences between the Crawford and CSMA strain were difficult to distinguish in gels developed for $30 \mathrm{~min}$, but the esterase band $a$ and $c$ from the Crawford strain were much more intense than those from CSMA. Moreover, the difference in intensities of these esterase bands between the Crawford and CSMA strain was more clearly identifiable in nymphs (Fig. 1) than in adults (Fig 2).

\section{Discussion}

The overproduction of nonspecific esterases in insecticide-resistant insects is well documented (Devonshire and Moores 1982, Cuany et al. 1993, Chen and Sun 1994). Increased esterase activity has been suspected as one of the major biochemical factors asso- ciated with insecticide resistance in German cockroach. Two resistant German cockroach strains, Dursban- $\mathbf{R}$ and Baygon- $\mathbf{R}$, exhibited enhanced activity toward $\alpha$-naphtholic esters relative to the standard susceptible CSMA strain (Siegfried and Scott 1992). Two other resistant strains, Macy and Pyr I, had higher hydrolytic activity toward $p$-nitro-phenyl acetate (Prabhakaran and Kamble 1996). Similar increased esterase activity toward both $\alpha$ - and $\beta$-NA was observed in the Crawford strain in our study. It was reported that $\alpha$-NA esterase activity was similar between nymphs and adults in the multiresistant Village Green strain, which is more tolerant of insecticides in its nymphal stages (Valles et al. 1994). But, our data show that the $\alpha$ - and $\beta$-NA esterase activities in nymphal stage were higher than in adults in the resistant Crawford strain but not in the susceptible CSMA strain. However, it is not possible to explain the relationship between the esterase activity and the difference of insecticide susceptibility against developmental stages in the Crawford strain without insecticide bioassay data.

Biochemical characterization of insecticide resistance in German cockroaches has been reported to involve the combined or individual effects of cytochrome $\mathrm{P}_{450}$ monooxygenases and hydrolytic ester- 


\section{Crawford $0^{7}$}

\section{CSMA ơ}

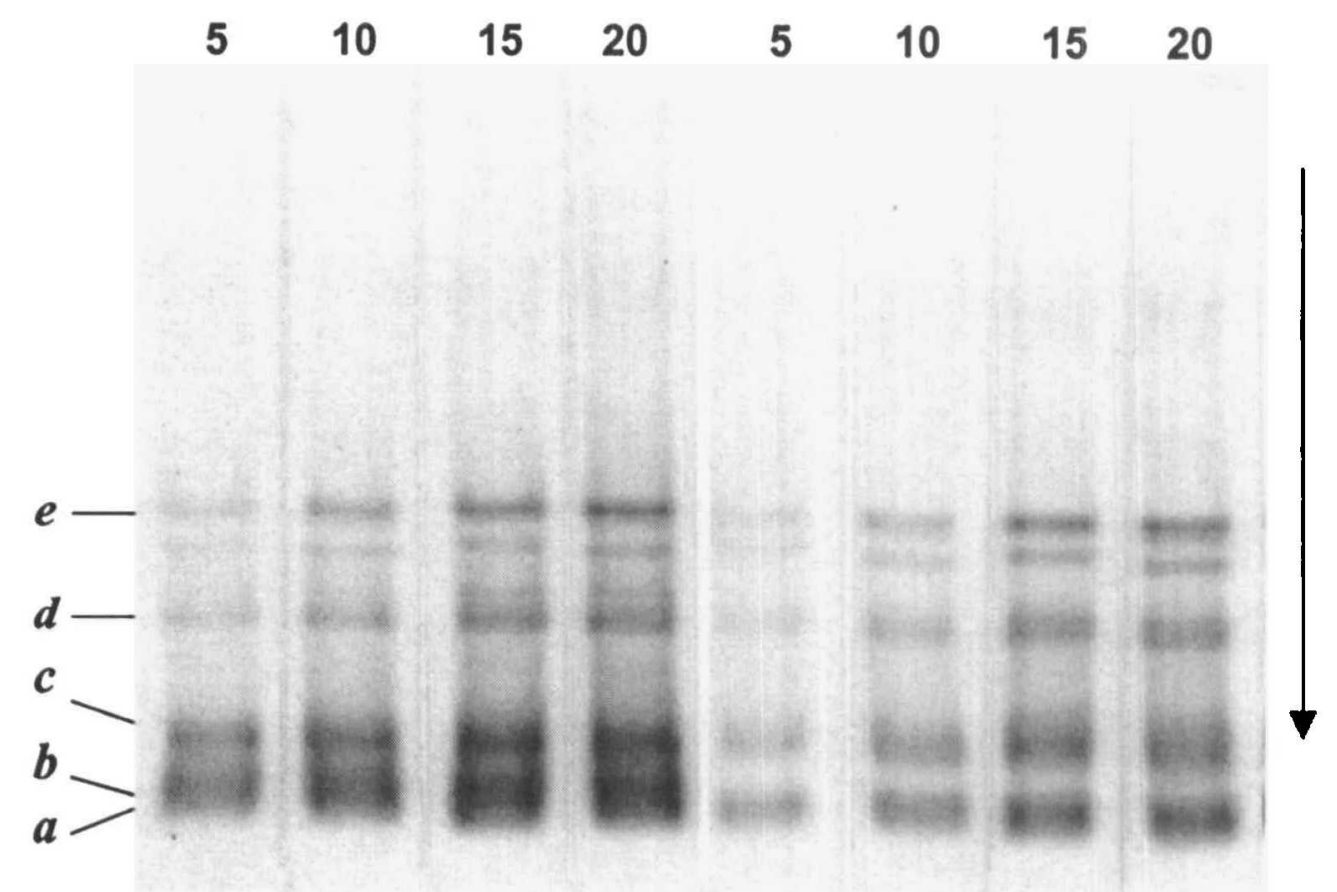

Fig. 3. Nonspecific esterase isozymes from adult males from the Crawford and CSMA strains of German cockroach, separated by native polyacrylamide gel electrophoresis. Esterase isozymes were visualized with $\alpha$-naphthyl acetate only, and all conditions were the same as the gel in Fig. 1, except incubation times of $5,10,15$, and 20 min during the enzyme activity development in the native gel. Numbers above each lane indicate the incubation time (minutes). Letters $a-e$ indicate the 5 major isozyme bands of increasing mobility in the native gels. See the text for details.

ases. These enzymes are responsible for the oxidation, hydrolysis, and sequestration of the toxic materials (Siegfried and Scott 1992; Hemingway et al. 1993; Anspaugh et al, 1994; Prabhakaran and Kamble 1995, 1996; Scharf et al. 1996). Although the nonspecific esterase activity in the Crawford strain was signifcantly higher than that in the susceptible CSMA strain, other biochemical mechanisms may also be involved in the high resistance of the Crawford strain.

Native polyacrylamide gel electrophoresis is a valuable technique in the study of insect esterases and insecticide resistance. Esterase isozyme patterns after staining for enzymatic activity can be compared with each other to detect genetic variation within and among populations. Moreover, the characteristics of each esterase isozyme can be determined by the addition of specific substrates and inhibitors in the process of enzymatic staining of gels. Comparison of esterase isozyme patterns between resistant and susceptible German cockroach strains has been reported previously. The most intensely staining band in the Baygon- $\mathrm{R}$ strain was esterase $\mathrm{C}$, which appeared at the bottom of the lane, whereas in the Dursban-R strain, esterase $H$ and $I$ appeared at the upper middle of the lane (Siegfried and Scott 1992). In the Macy strain, the field-collected multiresistant strain, E6-9 appeared at the middle to lower region of the gel was highly stained with $\alpha$-naphthyl acetate (Prabhaka- ran and Kamble 1996). However, the isozyme pattern of the Crawford strain shows that more intensely stained bands were isozymes $a, b$, and $c$ in the bottom of the lane (Figs. 1 and 2). The relative intensity of the esterases $a$, $b$, and $c$ were more obvious after the incubation with only $\alpha$-NA for short periods (Fig. 3). The higher activities of the esterase $a, b$, and $c$ in the Crawford strain are most apparent in Fig. 3, after varying incubation periods. The esterases $a$ and $c$ were most intense in the Crawford and CSMA strains just after incubation for $5 \mathrm{~min}$, and the esterase $b$ occurred only in the Crawford strain. The intensities of these 3 bands in the Crawford strain were much greater than in the CSMA strain at all incubation times. This indicates that the total nonspecific esterase activity is dominated by the esterase $a, b$, and $c$ in the Crawford strain and esterase $a$ and $c$ in the CSMA strain. The enhanced activities of the esterase $a, b$, and $c$ in the Crawford strain are probably responsible for the higher nonspecific esterase activity in this strain across all developmental stages. These esterases are apparently responsible for a significant proportion of the total activity toward $\alpha$-naphthyl acetate based on the limited staining of other esterase bands.

The combination of the unique esterase $b$ and the overproduced esterase $a$ and $c$ in the Crawford strain can account for the substantial difference in total esterase activity between the CSMA and Crawford strains. Inhi- 
bition and metabolism studies using purified isozymes and insecticidal substrates will be essential to identify the involvement of these isozymes in insecticide resistance. Further, molecular characterization also will be valuable to understanding the physiological function of these isozymes toward endogenous substrates. Studies of these enzymes also will provide essential information required for the management of resistance in German cockroaches through the rapid identification of resistant individuals.

\section{Acknowledgments}

We are grateful to $G$. Sarath (Department of Biochemistry, University of Nebraska-Lincoln) for his review of an early draft of the manuscript, and M. H. Ross (Department of Fintomology, Virginia Polytechnic Institute and State University) for providing the Crawford strain of German cockroach. We also thank B. D. Siegfried and M. E. Scharf (Department of Entomology, University of Nebraska-Lincoln) for their critical review of the manuscript. This article is published as paper No. 12215, Journal Series, Nebraska Agricultural Division and contribution No. 983, Department of Eintomology, Institute of Agriculture and Natural Resources, University of Nebraska-Lincoln.

\section{References Cited}

Abbott, W. S. 1925. A method of computing the effectiveness of an insecticide. J. Econ. Entomol. 18: 265-267.

Abdel-Aal, Y.A.I., E. P. Lampert, R. M. Roe, and P. J. Semtner. 1992. Diagnostic esterases and insecticide resistance in the tobacco aphid, Myzus nicotianae Blackman (Homoptera: Aphididae). Pestic. Biochem. Physiol. 43: 123-133.

Anspaugh, D. G., R. L. Rose, P. K. Koelher, E. Hodgson, and R. M. Roe. 1994. Multiple mechanisms of pyrethroid resistance in the German cockroach. Pestic. Biochem. Physiol. 50: 138-148.

Bradford, M. M. 1976. A rapid and sensitive method for the quantitation of microgram quantities of protein utilizing the principle of protein dye binding. Anal. Biochem. 72: 248-254.

Byrne, F. J., and A. L. Devonshire. 1991. In vivo inhibition of esterase and acetylcholinesterase activities by profenofos treatments in the tobacco whitefly Bemisia tabaci (Genn.): implication for routine biochemical monitoring of these enzymes. Pestic. Biochem. Physiol. 40: 198-204.

Chen, W. I., and C. N. Sun. 1994. Purification and characterization of carboxyl esterase of rice brown planthopper, $\mathrm{Ni}$ laparzata lugens Stal. Insect Biochem. Mol. Biol. 24: 347-355.

Cochran, D. G., J. M. Grayson, and A. B. Gurney. 1972. Cockroaches-biology and control. WHO Mond. Sante WHO/VBC 75:576.

Cochran, D. G. 1989. Monitoring for insecticide resistance in field-collected strains of the German cockroach (Dictyoptera: Blattellidae). J. Econ. Entomol. 82: 336-341.

Cuany, A., J. Handani, J. Berge, D. Fournier, M. Raymond, G. P. Georghiou, and N. Pasteur. 1993. Action of esterase B1 on chlorpyrifos in organo phosphate resistant Culex mosquitoes. Pestic. Biochem. Physiol. 45: 1-6.

Dauterman, W. C. 1985. Insect metabolism: extramicrosomal, pp. 713-730. In G. A. Kerkut and L. I. Gilbert [eds.], Comprehensive insect physiology biochemistry and pharmacology, vol. 12. Pergamon, Oxford.

Devonshire, A. I.., and G. D. Moores. 1982. A carboxylesterase with broad substrate specificity causes organophosphorous, carbamate and pyrethroid resistance in peachpotato aphids. Pestic. Biochem. Physiol. 18: 235-246.
Frishman, A. M., and I. E. Alcamo. 1977. Domestic cockroaches and human bacterial disease. Pest Control 45: $16-$ 46.

Grayson, J. M. 1963. Further selection of normal and chlordane-resistant German cockroachs for resistance to malathion and diazinon. J. Econ. Entomol, 56: 447-449.

Hemingway, J., G. J. Small, and A. G. Monro. 1993. Possible mechanism of organophosphate and carbamate insecticide resistance in German cockroaches from different geographical areas. J. Econ. Entomol. 86: 1623-1630.

Maa, W. C., and L. C. Terriere. 1983. Age-dependent variation in enzymatic and electrophoresis properties of house fly (M. Domestica) carboxylesterases. Comp. Biochem. Physiol. 74C: 461-467.

Pasteur, N., and G. P. Georghiou. 1989. Improved filter paper test for detecting and quantifying increased esterase activity in organophosphate-resistant mosquitoes (Diptera: Culicidae). J. Econ. Entomol. 82: 347-353.

Prabhakaran, S. K. and S. T. Kamble. 1995. Purification and characterization of an esterase isozyme from insecticide resistant and susceptible strains of German cockroach, Blattella germanica (L). Insect Biochem. Mol. Biol. 25: 519-524

Prabhakaran, S. K., and S. T. Kamble. 1996. Biochemical characterization and purification of esterases from three strains of German cockroach, Blattella germanica. Arch. Insect Biochem. 31: 73-86.

Raymond, M. 1985. Presentation d'un programme d'analyse log-probit pour micro-ordinnateur. Cah. ORSTOM Ser. Entomol. Med. Parasitol. 22: 117-121.

Rust, M. K., and D. A. Reierson. 1991. Chlorpyrifos resistance in German cockroaches (Dictyoptera: Blattellidae) from restaurants. J. Econ. Entomol. 84: 736-740.

Schal, C. 1988. Relation among efficacy of insecticides, resistance levels, and sanitation in the control of the German cockroach. J. Econ. Entomol. 81: 536-544.

Scharf, M. E., J. Hemingway, B. L. Reid, G. J. Small, and G. W. Bennet. 1996. Toxicological and biochemical characterization of insecticide resistance in a field-collected strain of Blattella germanica (Dictyoptera: Blattellidae). J. Econ. Entomol, 89: 322-331.

Scharf, M. E., J. Hemingway, G. J. Small, G. W. Bennett. 1997. Examination of esterase from insecticide resistant and susceptible strains of the German cockroach, Blattella germanica (L.). Insect Biochem. Mol. Biol. 27: 489-497.

Siegfried, B. D., and J. G. Scott. 1992. Biochemical characterization of hydrolytic and oxidative enzymes in insecticide resistant and susceptible strains of the German cockroach (Dictyoptera: Blattellidae). J. Econ. Entomol. 85: 1092-1098.

Soderlund, D. M., and J. R. Bloomquist. 1990. Molecular mechanisms of insecticide resistance, pp. 58-97. In R. T. Roush and B. E. Tabashnik [eds.], Pesticide resistance in arthropods. Chapman \& Hall, New York.

Valles, S. M., S. J. Yu, and P. G. Koehler. 1994. Detoxifying enzymes in adults and nymphs of the German cockroaches: evidence for different microsomal monooxygenase systems. Pestic. Biochem. Physiol. 49: 183-190.

Van Asperen, K. 1962. A study of housefly esterases by means of a sensitive colorimetric method. J. Insect Physiol. 8: 401-416.

Zhai, J., and W. H. Robinson. 1992. Measuring cypermethrin resistance in the German cockroach. J. Econ. Entomol. 85: 348-351.

Received for publication 23 April 1998; accepted 23 June 1998 